\title{
Prediction of Midline Dose from Entrance and Exit Dose Using OSLD Measurements for Total Body Irradiation
}

\author{
Chang Heon Choi ${ }^{1,2,3}$, Jong Min Park ${ }^{1,2,3,4}$, So-Yeon Park ${ }^{1,2,3}$, Minsoo Chun ${ }^{1,2,3,5}$, Ji Hye Han ${ }^{1,3}$, Jin Dong Cho ${ }^{1,3}$, \\ Jung-in $\operatorname{Kim}^{1,2,3, *}$ \\ ${ }^{1}$ Department of Radiation Oncology, Seoul National University Hospital, Seoul, Korea; ${ }^{2}$ Institute of Radiation Medicine, Seoul National University Medical \\ Research Center, Seoul, Korea ; ${ }^{3}$ Biomedical Research Institute, Seoul National University College of Medicine, Seoul, Korea; ${ }^{4}$ Center for Convergence Research \\ on Robotics, Advance Institutes of Convergence Technology, Suwon, Korea; ${ }^{5}$ Interdisciplinary Program in Radiation Applied Life Science, Seoul National \\ University College of Medicine, Seoul, Korea
}

Background: This study aims to predict the midline dose based on the entrance and exit doses from optically stimulated luminescence detector (OSLD) measurements for total body irradiation (TBI).

Materials and Methods: For TBI treatment, beam data sets were measured for $6 \mathrm{MV}$ and 15 MV beams. To evaluate the tissue lateral effect of various thicknesses, the midline dose and peak dose were measured using a solid water phantom (SWP) and ion chamber. The entrance and exit doses were measured using OSLDs. OSLDs were attached onto the central beam axis at the entrance and exit surfaces of the phantom. The predicted midline dose was evaluated as the sum of the entrance and exit doses by OSLD measurement. The ratio of the entrance dose to the exit dose was evaluated at various thicknesses.

Received March 22, 2017

Revision May 4, 2017

Accepted May 11, 2017

Corresponding author: Jung-in Kim

Department of Radiation Oncology, Seoul National University Hospital, 101 Daehak-ro, Jongno-gu, Seoul 03080, Korea

Tel: +82-10-3835-1421

Fax: +82-2-765-3317

E-mail:madangin@gmail.com

This is an Open-Access article distributed under the terms of the Creative Commons Attribution NonCommercial License (http://creativecommons.org/ licenses/by-nc/4.0) which permits unrestricted noncommercial use, distribution, and reproduction in any medium, provided the original work is properly cited.

Copyright $\odot 2017$ The Korean Association for Radiation Protection

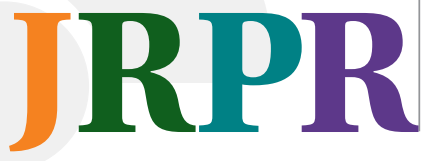

Results and Discussion: The ratio of the peak dose to the midline dose was 1.12 for a $30 \mathrm{~cm}$ thick SWP at both energies. When the patient thickness is greater than $30 \mathrm{~cm}$, the $15 \mathrm{MV}$ should be used to ensure dose homogeneity. The ratio of the entrance dose to the exit dose was less than 1.0 for thicknesses of less than $30 \mathrm{~cm}$ and $40 \mathrm{~cm}$ at $6 \mathrm{MV}$ and $15 \mathrm{MV}$, respectively. Therefore, the predicted midline dose can be underestimated for thinner body. At $15 \mathrm{MV}$, the ratios were approximately 1.06 for a thickness of $50 \mathrm{~cm}$. In cases where adult patients are treated with the $15 \mathrm{MV}$ photon beam, it is possible for the predicted midline dose to be overestimated for parts of the body with a thickness of $50 \mathrm{~cm}$ or greater.

Conclusion: The predicted midline dose and OSLD-measured midline dose depend on the phantom thickness. For in-vivo dosimetry of TBI, the measurement dose should be corrected in order to accurately predict the midline dose.

Keywords: OSLD, In vivo dosimetry, Total body irradiation (TBI), Midline dose

\section{Introduction}

Total body irradiation (TBI) is a specialized radiotherapy technique that delivers a uniform dose of within $\pm 10 \%$ of the prescribed dose to the entire body of the patient [1]. It is used to prepare a patient for bone marrow or stem cell transplantation by destroying the number of viable cells and suppressing the recipient's immune system 
with total body exposure [2-6]. TBI usually uses the extended source-to-surface distance (SSD) due to three reasons. The first reason is to be able to deliver the beam with a low dose rate of less than $10 \mathrm{cGymin}^{-1}$ by reducing the beam efficiency. The second reason is to allow a uniform dose distribution along the beam axis. The final reason is to be able to cover the entire body of the patient with large field sizes (e.g. $40 \times 40 \mathrm{~cm}^{2}$ ) [7-10].

The parallel-opposed lateral irradiation using extended SSD is the most preferred technique in TBI [11]. This stationary beam technique is very simple and is more comfortable for the patient than non-stationary beam techniques such as the translation beam and sweeping beam [12]. Moreover, the arms of the patient could be used as natural lung compensation for irradiation in the lateral direction in order to lower the risk of radiation-induced lung injury [12].

The tissue lateral effect is observed when a beam of insufficient energy is used for a patient which treated with parallel-opposed beams, and can give rise to an excessively higher dose to the peripheral regions compared to that of the midpoint [9]. The thicker the patient, the higher the beam energy required to produce acceptable dose uniformity for parallelopposed fields [9].

In TBI, the target volume is extended and has an irregular shape; therefore, it is necessary to define one representative point at which the prescribed dose is administered. This point is placed at the patient's midline and close to the abdomen or pelvis [13]. The TBI procedure delivers the prescribed dose to this reference point and should maintain the dose throughout the body to within $\pm 10 \%$ of the prescribed dose. The thickness variation along the medial axis of the patient and the patient diameter along the path of beam also affects dose uniformity. To achieve dose uniformity along the sagittal axis, compensators such as lead or copper plates are designed for the head, neck, shoulder, chest, umbilicus, hip, thigh, knee, calf, and ankle areas, respectively.

In vivo dosimetry should be executed with a dosimeter to verify the dose calculation and compensator design [14]. The entrance and exit doses are measured by in vivo dosimetry during treatment and are used to estimate the delivered midline doses [10]. However, it is difficult to predict the midline dose from entrance and exit dose measurements since these surface doses change depending upon the thickness and beam energy [15]. Satory developed an empirical formula to calculate the midline dose from MOSFET (metal-oxidesemiconductor field-effect transistor) measurements of the entrance and exit doses. The dependency of the surface dose on the air gap between the spoiler and the surface was investigated with various phantom thicknesses. The entrance and exit doses were combined using an exponential attenuation formula to give an estimate of the midline dose and this was compared to the midline ion chamber measurement for a range of phantom thicknesses [10]. Although there are many advantages of using MOSFETs, such as its portability, reproducibility, and direct readout capability, it is a quite cumbersome to install and attach the device to the surface of the patient since the MOSFET device requires a cable (to apply a voltage to the detector) and a dedicated reader device.

OSLDs have been well established to be suitable dosimeters for in vivo measurements due to their reproducibility, low energy dependence, small size, and ease of use [16]. OSLDs have high sensitivity and can measure a surface dose of patient with a non-destructive readout (i.e. without removal the cover or packing) and reanalysis using a simple readout system. Moreover, measurement accuracy can be improved using OSLDs with fully filled deep electron/hole traps and optimal bleaching conditions $[17,18]$.

In this study, the entrance and exit doses were measured using OSLDs at strategic locations. The strategic locations means the point which patient thickness was measured to fabricate a compensator.

The midline dose was predicted from these measured doses. We investigated the relationship between the midline dose and the surface dose for a range of patient thicknesses. The relationship was evaluated to predict the midline dose from entrance and exit dose measurements for $6 \mathrm{MV}$ and $15 \mathrm{MV}$.

\section{Materials and Methods}

\section{OSLD preparation}

InLight nanoDots (Landauer, Inc., Glenwood, IL) were used as the OSLDs. The OSLDs were pre-irradiated at a dose greater than $5 \mathrm{kGy}$ to fill the deep electron and hole traps by means of a ${ }^{60} \mathrm{Co}$ gamma ray source. The OSLDs were bleached to fall below the residual signal level over $4 \mathrm{~h}$. In our institution, the clinical dosimetry using OSLDs with fully filled deep electron/ hole traps under appropriate bleaching conditions have been shown to be highly stable and accurate, with no change in either the dose sensitivity or linearity. The uncertainty of OSLDs prepared by the process was less than $3 \%$. The R square of calibration curve was 0.99 within calibration range (20-500 cGy). 

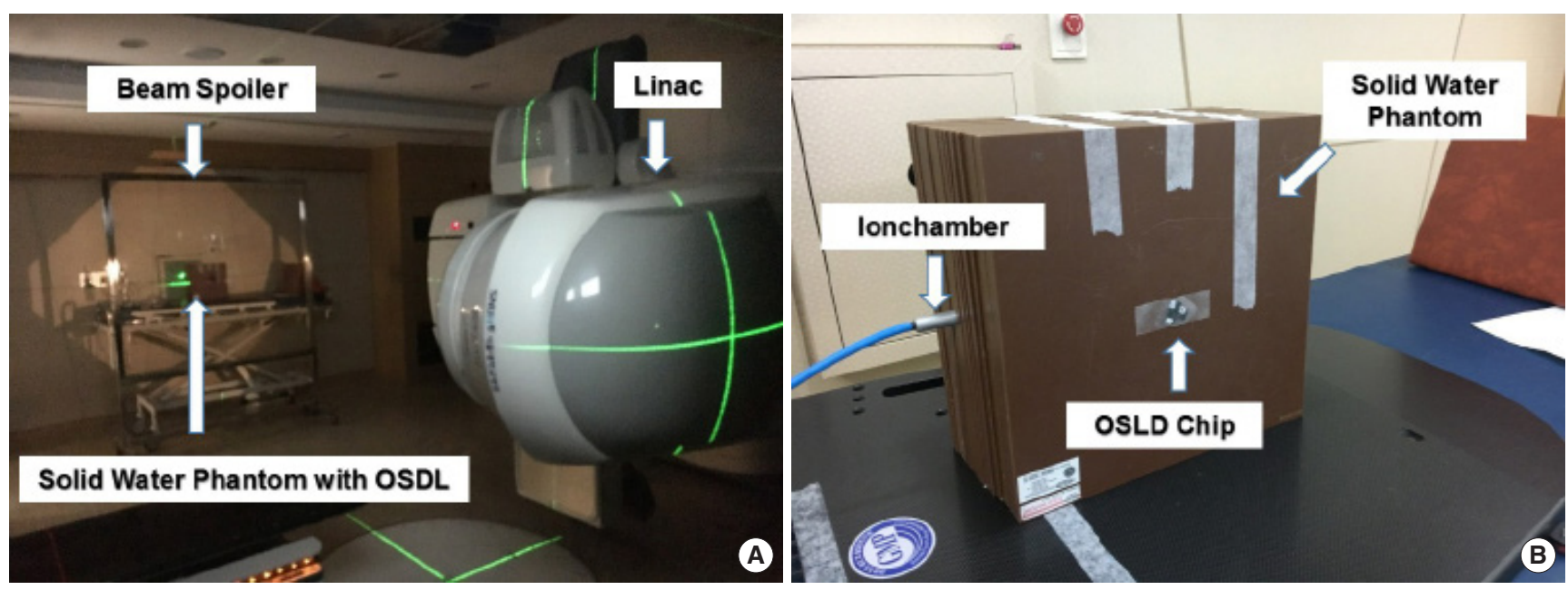

Fig. 1. Total body irradiation set-up with linac and solid water phantom (A), Measurement setup for measuring entrance, exit and midline dose with solid water phantom (B).

\section{TBI measurement}

Both the $6 \mathrm{MV}$ and $15 \mathrm{MV}$ photon beams were generated with a linear accelerator (Trilogy, Varian Medical Systems, Palo Alto, CA) for the TBI simulation. The midline of the patient was positioned $4 \mathrm{~m}$ from the source in consideration of the size of the treatment room, patient setup, and dose rate (Figure 1A). The extended SSD, tissue-maximum ratio (TMR), scatter factor, and transmission factors (block tray, beam spoiler, and compensator) were measured for $6 \mathrm{MV}$ and $15 \mathrm{MV}$, respectively. The transmission factors was defined as the ratio of the radiation dose with the device to the radiation dose without the device and accounts for the material in the beams path. The beam spoiler, which consisted of a $1 \mathrm{~cm}$-thick acrylic screen, was positioned in the path of the beam to increase the surface dose to the patient.

To determine the midline dose $\left(\mathrm{D}_{\mathrm{m} \_ \text {mid }}\right)$, the dose conversion factor was derived. When one hundred MU (monitor units) was delivered for the reference setup (SSD: $100 \mathrm{~cm}$, field size: $10 \mathrm{~cm} \times 10 \mathrm{~cm}$ ), the integrated coulomb measurement at the depth of the maximum dose $\left(\mathrm{d}_{\max }\right)$ was measured using a Farmer-type chamber (TN30013, PTW, Freiburg, Germany) and an electrometer (Uniods E, PTW, Freiburg, Germany) in a solid water phantom (SWP, Virtual Watert $^{\mathrm{TM}}$, Radiation Products Design Inc., Albertville, MN) for $6 \mathrm{MV}$ and $15 \mathrm{MV}$. The dose conversion factor was defined as the measured coulomb (C) at $d_{\max }$ when one hundred monitoring unit was delivered. The unit of dose conversion factor was $C \cdot G y^{-1}$.

The $D_{m \_ \text {mid }}$ was measured using the Farmer-type chamber that was inserted into a hole in a SWP slab of $2 \mathrm{~cm}$ thickness.
The chamber was placed at the midline along the central axis of the beam. The coulomb measurements were converted to dose units (Gy) using the dose conversion factor. The solid water phantom slabs were added in order to achieve the desired thickness. In this study, the measurement was performed for a range of phantom thicknesses $(6 \mathrm{~cm}, 10 \mathrm{~cm}, 16$ $\mathrm{cm}, 20 \mathrm{~cm}, 22 \mathrm{~cm}, 26 \mathrm{~cm}, 30 \mathrm{~cm}, 36 \mathrm{~cm}, 40 \mathrm{~cm}, 46 \mathrm{~cm}$, and 50 $\mathrm{cm})$. To evaluate the dose homogeneity due to the tissue lateral effect for the patient, the dose at a depth of $1 \mathrm{~cm}\left(D_{\text {peak }}\right)$ was measured using the Farmer-type chamber. The ratio of $\mathrm{D}_{\text {peak }}$ to $\mathrm{D}_{\mathrm{m} \_ \text {mid }}$ was calculated for each thickness.

OSLDs were placed on the central axis at the entrance and exit of the phantom to measure the entrance $\left(D_{\text {en }}\right)$ and exit $\left(D_{\text {ex }}\right)$ doses (Figure 1B). Three OSLDs were attached on each side to reduce measurement uncertainty. Solid water slabs of different thicknesses were joined in various combinations and attached to the front and back sides of the phantom for each energy. Considering dose homogeneity due to the tissue lateral effect, a $6 \mathrm{MV}$ photon beam was used for phantom thicknesses of $6 \mathrm{~cm}, 10 \mathrm{~cm}, 16 \mathrm{~cm}, 20 \mathrm{~cm}, 22 \mathrm{~cm}, 26 \mathrm{~cm}$, $30 \mathrm{~cm}$, and $36 \mathrm{~cm}$, and a $15 \mathrm{MV}$ photon beam was used for phantom thicknesses of $10 \mathrm{~cm}, 16 \mathrm{~cm}, 20 \mathrm{~cm}, 22 \mathrm{~cm}, 26 \mathrm{~cm}$, $30 \mathrm{~cm}, 36 \mathrm{~cm}, 40 \mathrm{~cm}, 46 \mathrm{~cm}$ and $50 \mathrm{~cm}$. In consideration of the fading effect, the OSLDs were read using the InLight MicroStar reader (Landauer, Inc., Glenwood, IL) 15 minutes after irradiation [18]. For a reliable reading of the nanoDot OSLDs, a readout was performed three times for each chip, and the predicted midline dose $\left(\mathrm{D}_{\mathrm{c} \_ \text {mid }}\right)$ was estimated as the sum of $D_{\text {en }}$ and $D_{\text {ex }}$. 


\section{Results and Discussion}

Table 1 shows the tray factor, spoiler factor, lead attenuation ratio per $1 \mathrm{~mm}$ thickness, and source to axis distance factor for $6 \mathrm{MV}$ and $15 \mathrm{MV}$. The maximum difference between the measured and calculated TMR data was within $2 \%$ and $1 \%$ for $6 \mathrm{MV}$ and $15 \mathrm{MV}$, respectively.

Figure 2 shows the plot of the ratio of $D_{\text {peak }}$ to $D_{m} \_$mid as a function of the phantom thickness for $6 \mathrm{MV}$ and $15 \mathrm{MV}$. As the thickness of the phantom was increased, $D_{\text {peak }}$ also increased rapidly and the lower the energy, the faster the increase. At $6 \mathrm{MV}$, the ratio increased to 1.32 at a SWP thickness of $36 \mathrm{~cm}$. When the SWP thickness was greater than $30 \mathrm{~cm}$, $\mathrm{D}_{\text {peak }}$ was greater than $10 \%$ of $\mathrm{D}_{\mathrm{m} \_ \text {mid }}$ at $6 \mathrm{MV}$. When $15 \mathrm{MV}$ was used at a SWP thickness of $50 \mathrm{~cm}, \mathrm{D}_{\text {peak }}$ increased to $125 \%$ of the midline dose. At a SWP thickness of $30 \mathrm{~cm}$, the ratio was 1.12 for both energies. Therefore, if the thickness of the patient is greater than $30 \mathrm{~cm}, 15 \mathrm{MV}$ should be used for treatment in order to achieve dose homogeneity [11].

Table 2 shows the values of $\mathrm{D}_{\mathrm{en}}, \mathrm{D}_{\mathrm{ex}}, \mathrm{D}_{\mathrm{c} \_ \text {mid }}, \mathrm{D}_{\mathrm{m} \_ \text {mid, }}$ and the ratio of $\mathrm{D}_{\mathrm{c} \_ \text {mid }}$ to $\mathrm{D}_{\mathrm{m} \_ \text {mid }}$ for $6 \mathrm{MV}$. Den was increased and $\mathrm{D}_{\mathrm{ex}}$ was decreased as the thickness of the SWP was increased. The ratio of $D_{c \_ \text {mid }}$ to $D_{m} \_$mid also increased with increasing SWP thickness. However, when the thickness of the SWP was increased from $10 \mathrm{~cm}$ to $16 \mathrm{~cm}$, the ratio decreased slightly because the increase of the entrance dose was smaller than the decrease of the exit dose. This is because the entrance dose depends on the distance between the spoiler and the surface of the entrance. For OSLDs measurements, the measurement

Table 1. Basic Parameter for Monitoring Unit Calculation about 6 and $15 \mathrm{MV}$

\begin{tabular}{ccccc}
\hline Energy (MV) & $\begin{array}{c}\text { Tray } \\
\text { Factor }\end{array}$ & $\begin{array}{c}\text { Spoiler } \\
\text { Factor }\end{array}$ & $\begin{array}{c}\text { Lead Attenuation } \\
\text { ratio }(\text { per mm) }\end{array}$ & $\begin{array}{c}\text { Source Axis } \\
\text { Distance Factor }\end{array}$ \\
\hline 6 & 0.968 & 0.973 & 0.943 & 0.064 \\
15 & 0.977 & 0.980 & 0.951 & 0.066 \\
\hline
\end{tabular}

point was included in the build-up region. Even though the SSD of the measurement point of the entrance dose was decreased, the dose did not increase considerably [10].

The ratio was approximately 1.0 at a SWP thickness of 30 $\mathrm{cm}$. For a pediatric patient, the thickness of most organs will be less than $30 \mathrm{~cm}$. In the case of the neck or ankle, the thickness will be almost $10 \mathrm{~cm}$. Therefore, we can estimate $D_{c \_ \text {mid }}$ to be less than $\mathrm{D}_{\mathrm{m} \_ \text {mid. }}$.

Table 3 shows the results of the 15 MV beam for the same data set as that of the $6 \mathrm{MV}$ beam. The results show a similar tendency to those at $6 \mathrm{MV}$; at SWP thicknesses between 10 $\mathrm{cm}$ and $22 \mathrm{~cm}$, the ratio decreased slightly. In this range, $\mathrm{D}_{\mathrm{c}_{-}}$

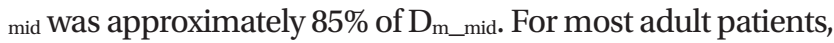
the thickness of the hips with both hands placed adjacent to the body is at least $40 \mathrm{~cm}$. Therefore, the $15 \mathrm{MV}$ beam was selected for treatment in consideration of the need for dose homogeneity. The thickness of the head and neck is slightly less than $25 \mathrm{~cm}$. Therefore, $\mathrm{D}_{\mathrm{c} \_ \text {mid }}$ at these areas of the body can fall below $\mathrm{D}_{\mathrm{m} \_ \text {mid. }}$. When the SWP thickness was greater

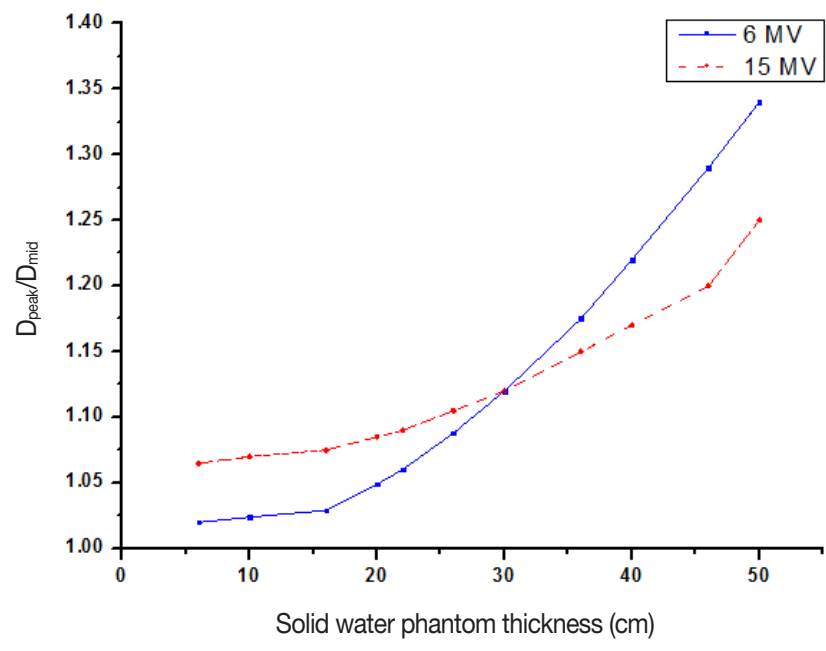

Fig. 2. The ratio of the dose at depth $1 \mathrm{~cm}$ to that of at the midline as a function of solid water phantom thickness for 6 and $15 \mathrm{MV}$.

Table 2. Comparison of Measured Midline Dose to Predicted Midline Dose Using OSLDs Exit and Entrance Dose Prediction for 6 MV

\begin{tabular}{|c|c|c|c|c|c|}
\hline Phantom Thickness & $\begin{array}{l}\text { Measured Midline dose } \\
\left.\text { ( } D_{\mathrm{m} \_ \text {mid }}\right)\end{array}$ & $\begin{array}{c}\text { Entrance dose } \\
\left(D_{e n}\right)\end{array}$ & $\begin{array}{l}\text { Exit dose } \\
\left(D_{e x}\right)\end{array}$ & $\begin{array}{l}\text { Predicted Midline dose } \\
\qquad\left(D_{\text {c_mid }}\right)\end{array}$ & $\begin{array}{l}\text { The ratio to } \\
D_{c \_ \text {mid }} \text { to } D_{m \_ \text {mid }}\end{array}$ \\
\hline 6 & 200.80 & 98.98 & 85.09 & 184.07 & 0.92 \\
\hline 10 & 200.44 & 106.42 & 79.88 & 186.30 & 0.93 \\
\hline 16 & 201.10 & 114.44 & 69.30 & 183.73 & 0.91 \\
\hline 20 & 200.56 & 121.97 & 66.95 & 188.91 & 0.94 \\
\hline 22 & 199.36 & 129.41 & 60.59 & 190.00 & 0.95 \\
\hline 26 & 200.46 & 136.72 & 59.23 & 195.95 & 0.98 \\
\hline 30 & 199.80 & 147.70 & 55.61 & 203.31 & 1.02 \\
\hline 36 & 199.22 & 161.11 & 50.84 & 211.94 & 1.06 \\
\hline
\end{tabular}


Table 3. Comparison of Measured Midline Dose to Predicted Midline Dose Using OSLDs Exit and Entrance Dose Prediction for 15 MV

\begin{tabular}{lccccc}
\hline Phantom Thickness & $\begin{array}{c}\text { Measured Midline dose } \\
\left(D_{\text {m_mid }}\right)\end{array}$ & $\begin{array}{c}\text { Entrance dose } \\
\left(D_{\text {en }}\right)\end{array}$ & $\begin{array}{c}\text { Exit dose } \\
\left(D_{\text {ex }}\right)\end{array}$ & $\begin{array}{c}\text { Predicted Midline dose } \\
\left(D_{\text {c_mid }}\right)\end{array}$ & $\begin{array}{c}\text { The ratio to } \\
D_{\text {c_mid }} \text { to } D_{\text {m_mid }}\end{array}$ \\
\hline 10 & 201.01 & 96.37 & 77.17 & 169.00 & 0.84 \\
16 & 200.16 & 100.28 & 70.46 & 170.74 & 0.85 \\
20 & 199.26 & 105.47 & 65.74 & 171.21 & 0.86 \\
22 & 200.86 & 112.66 & 63.40 & 176.06 & 0.88 \\
26 & 200.44 & 119.91 & 61.08 & 180.99 & 0.90 \\
30 & 200.48 & 125.07 & 58.02 & 183.09 & 0.91 \\
36 & 199.00 & 136.19 & 53.79 & 189.97 & 0.95 \\
40 & 199.06 & 146.60 & 50.64 & 197.24 & 0.99 \\
56 & 199.46 & 159.60 & 48.13 & 207.73 & 1.04 \\
\hline
\end{tabular}

than $20 \mathrm{~cm}$, the ratio increased in keeping with the SWP thickness. If the SWP thickness exceeded $46 \mathrm{~cm}$, the ratio was greater than 1 . Most obese patients have organ thicknesses of greater than $50 \mathrm{~cm}$ thickness at the shoulder, chest, umbilicus, and hip. $D_{c \_ \text {mid }}$ of these points can exceed over $10 \%$ of the prescription dose. $\mathrm{D}_{\mathrm{c} \_ \text {mid }}$ at $15 \mathrm{MV}$ was estimated to be lower than that of $6 \mathrm{MV}$ for same thickness. For $15 \mathrm{MV}$, a beam spoiler plate of $1 \mathrm{~cm}$ thickness is insufficient to produce the initial dose buildup region [10].

\section{Conclusion}

For TBI treatment, the acceptable range of dose homogeneity is $10 \%$ for most protocols. However, the predicted midline dose by entrance and exit dose measurement can be overestimated even though the real delivered dose is within the acceptable range. The midline dose cannot be predicted accurately from the entrance and exit dose measurements with OSLDs due to an insufficiently full build-up region and the lack of backscatter material. In addition, the tissue lateral effect is varies for different thicknesses at the calculation point.

Therefore, we need a correction to estimate the midline dose using the entrance and exit dose measurements. However, this correction changes for different thicknesses. The predicted midline dose can be corrected with the proper factor for each calculation point. Consequentially, we can predict a more accurate midline dose using the correction factor and surface dose.

In this study, the SWP we have used have discrete thicknesses due to the SWP combination limitations. Therefore, we need to investigate the relationship between the midline dose and the thickness of the SWP with finer resolution.

\section{Acknowledgements}

This study was supported by a grant from the National R\&D Program for Cancer Control, Ministry of Health \& Welfare, Republic of Korea (No. 1631200).

\section{References}

1. Keane T, Van Dyk JRider W. Idiopathic interstitial pneumonia following bone marrow transplantation: the relationship with total body irradiation. Int. J. Radiat. Oncol. Biol. Phys. 1981;7(10): 1365-1370.

2. Kim TH, Khan FMGalvin JM. A report of the work party: Comparison of total body irradiation techniques for bone marrow transplantation. Int. J. Radiat. Oncol. Biol. Phys. 1980;6(6):779784.

3. Appelbaum FR, Sullivan K, Buckner C, Clift R, Deeg HJ, Fefer A, Hill R, Mortimer J, Neiman PE, Sanders JE. Treatment of malignant lymphoma in 100 patients with chemotherapy, total body irradiation, and marrow transplantation. J. Clin. Oncol. 1987; 5(9):1340-1347.

4. Li R, Polishchuk A, DuBois S, Hawkins R, Lee SW, Bagatell R, Shusterman S, Hill-Kayser C. Patterns of relapse in high-risk neuroblastoma patients treated with and without total body irradiation. Int. J. Radiat. Oncol. Biol. Phys. 2017;97(2):270-277.

5. Reyzadeoglu M, Oysul K, Dirican B, Arpaci F, Balkan A, Surenkok S, Pak Y. Effect of dose-rate and lung dose in total body irradiation on interstitial pneumonitis after bone marrow transplantation. Tohoku J. Exp. Med. 2004;202(4):255-263.

6. Kim MH, Rhu SY, Lim DS, Song JY. Effects of low-dose fractionated total body irradiation on murine immune system. J. Radiat. Prot. Res. 2014;39(3):134-141.

7. Andreoli S, Bianchi C, Colleoni P, Fortunato M. Dosimetry in total body irradiation: A measurement set to characterize the treatment technique. Physica Med. 2016;32:1. 
8. Koch N, Jacqmin D, Mart C, Fugal M, Ashenafi M, Vanek K. Total body irradiation using dynamic arc delivery. Int. J. Radiat. Oncol. Biol. Phys. 2016;96(2):E640.

9. Khan FM. The physics of radiation therapy. 3rd Ed. Philadelphia, PA. Williams and Wilkins. 2002;455-465.

10. Satory P. Calculation of midplane dose for total body irradiation from entrance and exit dose MOSFET measurements. Australas. Phys. Eng. Sci. Med. 2012;35(1):101-104.

11. Van Dyk J. Dosimetry for total body irradiation. Radiother. Oncol. 1987;9(2):107-118.

12. Quast U. Whole body radiotherapy: A TBI-guideline. J. Med. Phys. 2006;31(1):5-12.

13. Hui SK, Das RK, Thomadsen B, Henderson D. CT based analysis of dose homogeneity in total body irradiation using lateral beam. J. Appl. Clin. Med. Phys. 2004;5(4):71-79.

14. Akino Y, McMullen KP, Das IJ. Patterns of patient specific dosim- etry in total body irradiation. Med. Phys. 2013;40(4):01479 1-5.

15. Zhu X. Entrance dose measurements for in-vivo diode dosimetry: Comparison of correction factors for two types of commercial silicon diode detectors. J. Appl. Clin. Med. Phys. 2000;1(3): 100-107.

16. Mrčela I, Bokulić T, Izewska J, Budanec M, Fröbe AKusić Z. Optically stimulated luminescence in vivo dosimetry for radiotherapy: physical characterization and clinical measurements in ${ }^{60} \mathrm{Co}$ beams. Phys. Med. Biol. 2011;56(18):60-65.

17. Jursinic PA. Characterization of optically stimulated luminescent dosimeters, OSLDs, for clinical dosimetric measurements. Med. Phys. 2007;34(12):4594-4604.

18. Jursinic PA. Changes in optically stimulated luminescent dosimeter (OSLD) dosimetric characteristics with accumulated dose. Med. Phys. 2010;37(1):132-140. 